\title{
Clinical Outcomes of Acute Myocardial Infarction Patients With a History of Malignant Tumor
}

\author{
MASASHI NOZAKA, HIROAKI YOKOYAMA, KAZUTAKA KITAYAMA, DAIKI NAGAWA, \\ MISATO HAMADATE, NAOTAKE MIURA, YOSUKE KAWAMURA, MASAMICHI NAKATA, \\ FUMIE NISHIZAKI, KENJI HANADA, TAKASHI YOKOTA, MASAHIRO YAMADA and HIROFUMI TOMITA \\ Department of Cardiology and Nephrology, Hirosaki University Graduate School of Medicine, Hirosaki, Japan
}

\begin{abstract}
Background: Little is known about the clinical outcomes of acute myocardial infarction (AMI) in patients with a history of malignant tumor (MT). Patients and Methods: We retrospectively studied 1,295 consecutive patients with AMI who underwent primary percutaneous coronary intervention within 24 hours of onset. The patients were divided into two groups: those with a history of $M T$ (MT group, $n=50$ ) and those without (non-MT group, $n=1,245)$. Results: The MT group was older, and had lower hemoglobin, total protein, and albumin levels. All-cause mortality and re-admission rates due to acute decompensated heart failure $(A D H F)$ were significantly higher in the MT group. Multivariate analysis showed that a history of MT was an independent predictor for all-cause mortality and re-admission due to ADHF. Conclusion: The clinical outcomes of patients with AMI with a history of MT are poor, and a history of MT is an independent predictor for all-cause mortality and re-admission due to ADHF. These patients may need careful risk management for heart failure to avoid re-admissions due to $A D H F$.
\end{abstract}

Acute myocardial infarction (AMI) is a life-threatening disease that is common in developed countries. Although prognosis has improved dramatically since the development of primary percutaneous coronary intervention (PCI) in the early 1990s, ST elevation myocardial infarction (STEMI) still has a poor prognosis, with an in-hospital mortality rate of $7.1 \%$ in Japan (1). Another fatal disease is the

This article is freely accessible online.

Correspondence to: Hirofumi Tomita, MD, Ph.D., Department of Cardiology and Nephrology, Hirosaki University Graduate School of Medicine, 5 Zaifu-cho, Hirosaki, 036-8562 Japan. Tel: +81 172395057, Fax: +81 172359190, e-mail: tomitah@hirosaki-u.ac.jp

Key Words: Malignant tumor, heart failure, acute myocardial infarction. development of a malignant tumor (MT) (2). Previous studies have shown a close relation between MTs and cardiovascular disease. MTs themselves cause venous or arterial thrombosis due to abnormal coagulation, platelet activation, and endothelial dysfunction (3). Regarding the treatment for MT, modern treatment strategies have improved relapse-free survival but they often induce the development of cardiovascular disease. Chemotherapy, such as with classical therapeutic drugs and molecular targeted drugs, and radiotherapy sometimes cause heart failure, thrombosis, ischemic heart disease, valvular disease, and hypertension $(4,5)$. Previous studies have reported that MTs adversely affect the development of cardiovascular disease but only few reports have investigated the clinical outcomes of AMI patients with a history of MT. In the present study, we investigated the clinical characteristics and outcomes of patients with AMI with a history of MT.

\section{Patients and Methods}

Study population. We retrospectively studied 1,295 consecutive patients with AMI who were admitted to our hospital and underwent primary PCI within 24 hours from the onset of symptoms between January 2007 and December 2016. The patients who were admitted to our hospital after 24 hours from onset or those who did not undergo primary PCI were excluded. The patients were divided into two groups as follows: those who had a history of MT and those without. The MT group consisted of patients who had a past history of MT and those who were diagnosed during hospitalization for AMI treatment. Moreover, we included the patients who had received treatment for a MT in the past and who were not under treatment at the time of AMI onset. Patients who had a diagnosis of a MT after discharge for AMI treatment were placed in the non-MT group. We compared the clinical characteristics of AMI and outcomes between the two groups. This study complied with the Declaration of Helsinki and was approved by the ethics committee of our institution.

Diagnosis and PCI procedure. AMI was diagnosed according to the universal definition (6), and all study patients underwent primary PCI within 24 hours of the onset of symptoms. The indication for and the strategy of the PCI procedure were left to the clinical 
physician as whether they used the coronary stent or not, as was antiplatelet therapy. Acute decompensated heart failure (ADHF) was diagnosed according to the Framingham criteria (7).

Clinical outcomes of study patients. The endpoints of this study were all-cause mortality and re-admission due to ADHF. The median follow-up period was 3.8 (1.7-6.6) years. Follow-up data were obtained from reviewing patients' hospital records, interviewing the patients by telephone, and examining the patients in outpatient clinics.

Statistical analyses. Categorical outcomes were expressed as counts and percentages, and they were compared using chisquared test or Fisher exact test. Normally distributed data are reported as the mean \pm standard deviation, while non-normally distributed data are reported using quartiles. Continuous variables were compared by Student's $t$-test when normally distributed, or Mann-Whitney $U$-test when non-normally distributed. KaplanMeier curves for all-cause mortality and re-admission due to ADHF were compared between the two groups, and were evaluated using log-rank test. Multivariate analyses using Cox proportional hazards model were performed to identify independent prognostic factors for all-cause mortality and readmission due to ADHF, and hazard ratios (HR) and 95\% confidence intervals $(\mathrm{CI})$ were reported. Univariate predictors that had a value of $p<0.10$ were considered in the multivariate Cox proportional hazards model. Analyses were performed using JMP Pro software version 13 (SAS, Cary, NC, USA). A p-value of less than 0.05 was considered statistically significant.

\section{Results}

Characteristics of the study patients. Of the 1,295 consecutive patients with AMI, 50 (3.9\%) had a history of MT. Of these, at the time of AMI admission, $14(28 \%)$ were receiving some kind of treatment for a MT, while nine (18\%) were not receiving any treatment whatsoever. There were 24 patients (48\%) who completed the treatment, including surgical resection of the MT, chemotherapy, or radiation therapy at the time of AMI admission, and they were all under careful observation. The remaining three patients $(6 \%)$ were diagnosed with a MT before AMI onset; however, we were unable to evaluate whether they received some kind of treatment at the time of AMI admission. In the present study, the most frequent types of MT were of the colon (31\%), followed by the prostate (19\%), stomach (15\%), breast (15\%), and lung $(10 \%)$. The duration of the treatment and chemotherapy regimen were not evaluated. Baseline characteristics of the study patients are shown in Table I. Patients of the MT group were significantly older than those of the non-MT group. There were no significant differences in gender, coronary risk factors (except smoking habit), previous MI, or previous invasive coronary intervention. Killip classification (8) at admission, culprit vessel, and presence of multivessel disease did not differ between the two groups. There were more patients who underwent primary PCI without stenting in the MT group compared to those in the non-MT group. There was no difference in the final thrombolysis in myocardial infarction (TIMI) grade (9) after primary PCI despite the lower frequency of stenting in the MT group. The time from onset-to-balloon inflation was significantly longer in the MT group compared with the non-MT group; however, maximum creatine phosphokinase (CPK) and CPK-MB isoenzyme (CPK-MB) levels were lower in the MT group. The proportion of patients that developed complications, such as atrial fibrillation or flutter, was similar for the two groups, and there were no differences in antithrombotic medical therapies, including antiplatelet and anticoagulant, at the time of admission. Moreover, there were no differences in antithrombotic medical therapies at the time of hospital discharge. Hemoglobin, total protein, and albumin levels were significantly lower, and the body mass index tended to be lower in the MT group than in the non-MT group.

Relationship between a history of MT and clinical outcome. During the follow-up period, a total of 263 patients died, 124 of whom as a result of cardiac death. Kaplan-Meier curves showed that all-cause mortality was significantly higher in the MT group compared with the non-MT group (60\% vs. 33\%, $p<0.001$; Figure 1A). There was no difference in cardiac death rate between the two groups (11\% in MT vs. $13 \%$ in non-MT, $p=0.78$; Figure 1B), although the MT group had a worse non-cardiac death rate compared to the non-MT group (46\% vs. 19\%, $p<0.001$; Figure 1C). The most frequent cause of cardiac death was ADHF in both groups. In the MT group, 19 patients died during the observational period, and nine of them died because of MT (Table II). On the other hand, 41 patients died due to MT in the non-MT group, and they were all diagnosed as having MT after discharge for AMI. As described above, although there was no difference in cardiac death between the two groups, re-admission due to ADHF was more frequently observed in the MT group compared to the non-MT group (29\% vs. 13\%, $p=0.012$; Figure 1D).

Predictors of clinical outcome. Multivariate Cox proportional hazards analysis showed that a history of MT was significantly associated with higher incidence of all-cause mortality $(\mathrm{HR}=1.97$; 95\% CI=1.19-3.08, $p<0.05$; Table III). Other predictors for all-cause mortality were higher age, male gender, and ADHF during hospitalization for AMI treatment. Although a history of MT was not associated with cardiac death, it was significantly associated with the need for re-admission due to $\mathrm{ADHF}(\mathrm{HR}=2.37$; 95\% $\mathrm{CI}=1.08$ 5.20, $p<0.05$; Table III).

\section{Discussion}

Major findings. In the present study, we showed that patients with AMI with a history of MT who underwent primary PCI within $24 \mathrm{~h}$ from onset of symptoms had worse all-cause 
Table I. Baseline characteristics of the study patients.

\begin{tabular}{|c|c|c|c|}
\hline Characteristic & MT $(n=50)$ & Non-MT $(\mathrm{n}=1,245)$ & $p$-Value \\
\hline Age, years & $74 \pm 9$ & $66 \pm 13$ & $<0.001$ \\
\hline Male gender, n (\%) & $38(76)$ & $982(79)$ & 0.63 \\
\hline BMI, $\mathrm{kg} / \mathrm{m}^{2}$ & $23.2 \pm 3.4$ & $24.2 \pm 3.6$ & 0.06 \\
\hline \multicolumn{4}{|l|}{ Coronary risk factor } \\
\hline Hypertension, n (\%) & $39(78)$ & $906(73)$ & 0.40 \\
\hline Dyslipidemia, n (\%) & $36(72)$ & $1,001(80)$ & 0.16 \\
\hline Diabetes mellitus, n (\%) & $26(52)$ & $607(49)$ & 0.65 \\
\hline Current smoker, n (\%) & $14(28)$ & $519(42)$ & 0.04 \\
\hline Previous MI, n (\%) & $4(8)$ & $122(10)$ & 0.67 \\
\hline Previous PCI, n (\%) & $6(12)$ & $105(8)$ & 0.40 \\
\hline Previous CABG, n (\%) & $0(0)$ & $17(1)$ & 0.25 \\
\hline Af/AFL, n (\%) & $8(16)$ & $149(12)$ & 0.41 \\
\hline Antiplatelet therapy, n (\%) & $4(11)$ & $121(14)$ & 0.58 \\
\hline Anticoagulant therapy, n (\%) & $1(3)$ & $31(4)$ & 0.77 \\
\hline Onset-to-balloon time, hours & $6.5(3.6-10.8)$ & $4.8(3.3-7.4)$ & 0.01 \\
\hline Killip classification, $\mathrm{n}(\%)$ & & & 0.21 \\
\hline I & $43(86)$ & $1,028(83)$ & \\
\hline II & $4(8)$ & $70(6)$ & \\
\hline III & $3(6)$ & $55(4)$ & \\
\hline IV & $0(0)$ & $92(7)$ & \\
\hline \multicolumn{4}{|l|}{ Blood chemistry at admission } \\
\hline Hemoglobin, g/dl & $12.3 \pm 2.3$ & $13.7 \pm 2.0$ & $<0.001$ \\
\hline Total-cholesterol, mg/dl & $180 \pm 47$ & $194 \pm 42$ & 0.02 \\
\hline LDL-cholesterol, mg/dl & $111 \pm 42$ & $122 \pm 37$ & 0.03 \\
\hline HDL-cholesterol, mg/dl & $47 \pm 15$ & $46 \pm 12$ & 0.76 \\
\hline Triglyceride, mg/dl & $114 \pm 125$ & $131 \pm 104$ & 0.27 \\
\hline Total protein, g/dl & $6.5 \pm 0.6$ & $6.7 \pm 0.6$ & 0.02 \\
\hline Albumin, g/dl & $3.7 \pm 0.5$ & $3.9 \pm 0.5$ & 0.002 \\
\hline BNP, pg/ml & $115(44-238)$ & $56(21-148)$ & 0.005 \\
\hline $\mathrm{eGFR}, \mathrm{ml} / \mathrm{min} / 1.73 \mathrm{~m}^{2}$ & $64.9 \pm 29.9$ & $70.4 \pm 26.5$ & 0.15 \\
\hline LVEF, \% & $45.0 \pm 10.6$ & $46.6 \pm 11.0$ & 0.33 \\
\hline Culprit vessel, n (\%) & & & 0.29 \\
\hline LMT & $1(2)$ & $43(3)$ & \\
\hline LAD & $24(49)$ & $572(46)$ & \\
\hline LCX & $3(6)$ & $174(14)$ & \\
\hline $\mathrm{RCA}$ & $21(43)$ & $456(37)$ & \\
\hline LMT or multi-vessel disease, $\mathrm{n}(\%)$ & $29(58)$ & $639(51)$ & 0.35 \\
\hline Final TIMI grade, n (\%) & & & 0.16 \\
\hline$<2$ & $10(20)$ & $190(18)$ & \\
\hline 3 & $40(80)$ & $841(82)$ & \\
\hline PCI procedure, n (\%) & & & 0.02 \\
\hline BMS & $37(76)$ & $899(73)$ & \\
\hline DES & $5(10)$ & $266(22)$ & \\
\hline Without stent & $7(14)$ & $73(6)$ & \\
\hline ADHF during hospitalization, $\mathrm{n}(\%)$ & $7(14)$ & $199(16)$ & 0.70 \\
\hline Max CPK, IU/1 & $2,126(591-3,186)$ & $2,476(1,121-4,494)$ & 0.03 \\
\hline Max CPK-MB, IU/1 & $211(64-365)$ & $246(113-461)$ & 0.04 \\
\hline
\end{tabular}

ADHF: Acute decompensated heart failure; Af/AFL: atrial fibrillation/atrial flutter; BMI: body mass index; BMS: bare metal stent; BNP: brain natriuretic peptide; CABG: coronary artery bypass grafting; CPK: creatine phosphokinase; CPK-MB: CPK-MB isoenzyme; DES: drug-eluting stent; eGFR: estimated glomerular filtration rate; HDL: high density lipoprotein; LAD: left anterior descending coronary artery; LCX: left circumflex coronary artery; LDL: low density lipoprotein; LMT: left main trunk; LVEF: left ventricular ejection fraction; MI: myocardial infarction; PCI: percutaneous coronary intervention; RCA: right coronary artery; TIMI: thrombolysis in myocardial infarction. Data are expressed as mean \pm standard deviation or median (interquartile range). Statistically significant $p$-values are shown in bold. 

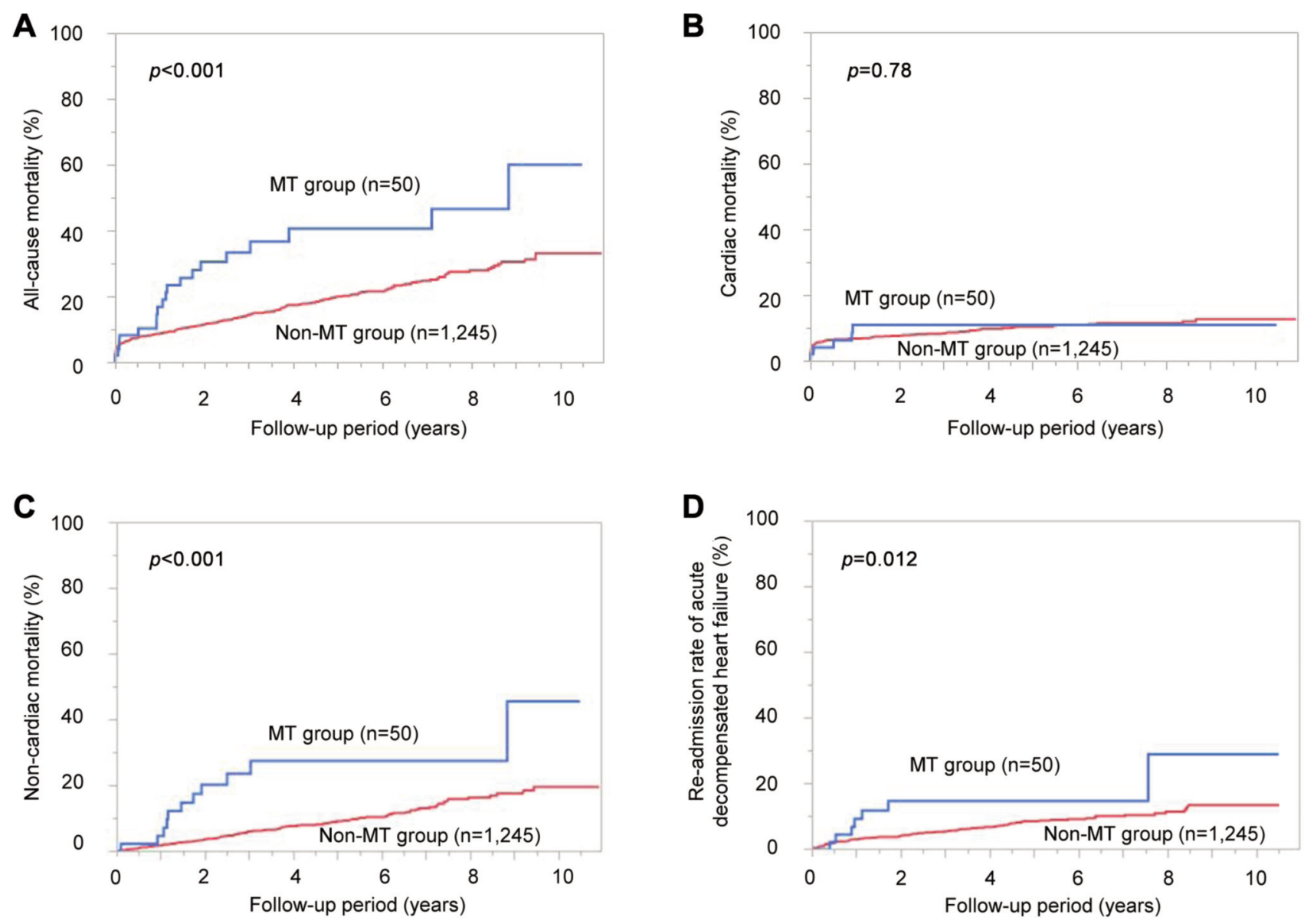

Figure 1. Kaplan-Meier curves for all-cause mortality $(A)$, cardiac death $(B)$, non-cardiac death $(C)$, and re-admission due to acute decompensated heart failure $(D)$ in patients with acute myocardial infarction with (MT) and without (non-MT) malignant tumor.

mortality and had a higher frequency of re-admission due to ADHF than those without. Moreover, a history of MT was an independent predictor of all-cause mortality and readmission due to ADHF.

Characteristics of AMI in patients with a history of MT. In this study, patients with AMI with a history of MT were older compared to those without it. Coronary risk factors except smoking habit were similar for the two groups. Additionally, a smoking habit was more frequently observed in the non-MT group. It is believed that the lower smoking rate in the MT group might have been due to previous diagnosis of MT which had led to smoking cessation. Onsetto-balloon time was longer in the MT group than in the nonMT group. In previous studies, elderly patients were reported to have a longer time from onset to reperfusion $(10,11)$, and patients with advanced MT sometimes had MT-related chest pain $(12,13)$. Thus, the time it takes to be treated from developing AMI may be longer in elderly patients with MT.
On the other hand, maximum CPK (CPK-MB) was lower in the MT group. Although there was no significant difference, there were more patients with TIMI grade 2 or more before PCI in the MT group. This might have contributed to a lower maximum CPK (CPK-MB) level in the MT group.

At the time of admission, total-cholesterol, low-density lipoprotein-cholesterol, total protein, and albumin levels were lower in the MT group. These patients may have been malnourished due to metabolic disorders, anorexia, premature satiety, reduced food intake, and older age (14-16). Moreover, there were more patients with anemia in the MT group. Anemia is one of the most common disorders in patients with a MT because of the effects of cytotoxic chemotherapy, nutritional deficiencies, bone marrow failure, blunted erythropoietin response, and inflammatory cytokines generated in response to tumors (17). Although some of the therapeutic drugs for MTs such as doxorubicin may cause left ventricular dysfunction due to cardiotoxicity (18) and heart failure, there was no difference in left ventricular ejection fraction between the two groups. 
Table II. Frequency and causes of death and re-admission due to acute decompensated heart failure in the study populations.

\begin{tabular}{|c|c|c|c|}
\hline Clinical outcome & $\operatorname{MT}(\mathrm{n}=50)$ & Non-MT $(n=1,245)$ & $p$-Value \\
\hline All-cause death, n (\%) & $19(38)$ & $244(20)$ & $<0.001$ \\
\hline Cardiac death, n (\%) & $5(10)$ & $119(10)$ & 0.78 \\
\hline Recurrence of MI & $0(0)$ & $29(2)$ & \\
\hline ADHF & $5(10)$ & $50(4)$ & \\
\hline Sudden cardia death & $0(0)$ & $26(2)$ & \\
\hline Heart rupture & $0(0)$ & $8(1)$ & \\
\hline Fatal arrhythmia & $0(0)$ & $6(1)$ & \\
\hline Non-cardiac death, n (\%) & $14(28)$ & $125(10)$ & $<0.001$ \\
\hline Malignant tumor & $9(18)$ & $41(3)$ & \\
\hline Other & $5(10)$ & $84(7)$ & \\
\hline Re-admission due to ADHF, $\mathrm{n}(\%)$ & $7(14)$ & $88(7)$ & 0.01 \\
\hline
\end{tabular}

ADHF: Acute decompensated heart failure MI: myocardial infarction MT: malignant tumor. Statistically significant $p$-values are shown in bold.

Table III. Multivariate analyses for the predictors of all-cause mortality and re-admission due to acute decompensated heart failure.

\begin{tabular}{|c|c|c|c|}
\hline Predictor & HR & $95 \% \mathrm{CI}$ & $p$-Value \\
\hline \multicolumn{4}{|l|}{ All-cause mortality } \\
\hline Age & 1.06 & $1.05-1.08$ & $<0.001$ \\
\hline Male gender & 1.45 & $1.08-1.96$ & 0.01 \\
\hline ADHF during hospitalization for AMI & 3.32 & $2.56-4.29$ & $<0.001$ \\
\hline History of malignant tumor & 1.97 & $1.19-3.08$ & 0.005 \\
\hline \multicolumn{4}{|l|}{ Re-admission due to ADHF } \\
\hline Age & 1.05 & $1.03-1.07$ & $<0.001$ \\
\hline Male gender & 1.07 & $0.58-1.50$ & 0.77 \\
\hline ADHF during hospitalization for AMI & 3.70 & $2.38-5.72$ & $<0.001$ \\
\hline History of malignant tumor & 2.37 & $1.08-5.20$ & 0.03 \\
\hline
\end{tabular}

ADHF: Acute decompensated heart failure; AMI: acute myocardial infarction; CI: confidence interval; HR: hazard ratio. Statistically significant $p$ values are shown in bold.

PCI to the patients with a history of MT. There were no differences in the culprit vessel of AMI nor the presence of multi-vessel disease between the two groups. However, there were more patients who underwent primary PCI without stenting in the MT group compared with the non-MT group. A possible reason for the lower frequency of stenting in the MT group might be derived from the presence of anemia at admission or scheduled surgery for their MT, which may be affected by dual antiplatelet therapy after stenting. Other reasons why PCI operators did not use a coronary stent might have been due to large vessel size or embolization of thrombus. Placement of coronary stent does not affect mortality but does reduce the risk of acute coronary occlusion and recurrence of MI compared to balloon angioplasty alone $(19,20)$. In this study, the recurrence of MI was comparable during the observation period. Moreover, despite the lower frequency of stenting in the MT group, there was no difference in antithrombotic medical therapies at the time of hospital discharge. Unfortunately, we were unable to evaluate the antithrombotic medical therapies after hospital discharge because of the lack of medical information.

Clinical outcomes of patients with AMI with a history of MT. Patients with AMI with MT had a significantly worse all-cause mortality compared with those without. Generally, the clinical outcomes of MT are poor, and many patients with a MT also died of non-cardiac death in this study. Patients with AMI with a MT had significantly worse non-cardiac mortality compared to those without, while there was no difference in cardiac death. Contrary to our results, Velders et al. had shown that STEMI patients with MT, especially those who were diagnosed with a MT within 6 months prior to STEMI onset, were at increased risk of cardiac death at 1-year (21). We enrolled patients who survived more than 5 years after the treatment of MT in the MT group, which in conjunction with the limited participants in our study may have affected the results.

Re-admission due to $A D H F$. Although there was no difference in cardiac death between the two groups, the patients in the 
MT group had a higher rate of re-admission due to ADHF. It is known that some treatments for MTs are related to myocardial injury (22). However, the relationship between treatment for MT and clinical outcomes of patients with AMI has not been fully evaluated. Re-admission due to ADHF was more frequently observed in the MT group, although the left ventricular ejection fraction was comparable between the two groups. Anemia and malnutrition including low body mass index, hypoalbuminemia, and hypocholesterolemia are known risk factors for heart failure (23-27). In addition, anemia and malnutrition are associated with aging and MTs. In patients with a history of MT, multiple risk factors such as high age, anemia, and poor nutritional status might have affected their clinical outcomes in the present study.

Study limitations. There are several limitations to the present study. Firstly, our results involved a retrospective analysis from a single-center. Secondly, the numbers of patients with AMI complicated with MT were small. Therefore, our results may not be generalizable. However, consecutive patients were studied, which may minimize bias involved in a retrospective study. Finally, due to a lack of medical information about the details of the treatment of MT, we were unable to evaluate the severity of the MT and the duration of the treatment, which might have affected the outcomes.

\section{Conclusion}

Patients with AMI with a history of MT who underwent primary PCI had worse outcomes and had higher frequency of re-admission due to ADHF compared to those without. Therefore, they may need careful risk management for heart failure to avoid re-admissions due to ADHF.

\section{Conflicts of Interest}

The Authors declare no conflicts of interest associated with this article.

\section{Authors' Contributions}

Conception: Masashi Nozaka, and Hirofumi Tomita. Study design: Masashi Nozaka, Hiroaki Yokoyama, and Hirofumi Tomita. Data collection and processing: Masashi Nozaka, Hiroaki Yokoyama, Kazutaka Kitayama, Daiki Nagawa, Misato Hamadate, Naotake Miura, Yosuke Kawamura, Masamichi Nakata, Fumie Nishizaki, Kenji Hanada, Takashi Yokota, and Masahiro Yamada. Article writing: Masashi Nozaka. Critical review: Hiroaki Yokoyama and Hirofumi Tomita.

\section{References}

1 Ishihara M, Fujino M, Ogawa H, Yasuda S, Noguchi T, Nakao K, Ozaki Y, Kimura K, Suwa S, Fujimoto K, Nakama Y, Morita T, Shimizu W, Saito Y, Tsujita K, Nishimura K and Miyamoto
Y: Clinical presentation, management and outcome of Japanese patients with acute myocardial infarction in the troponin era Japanese registry of acute myocardial infarction diagnosed by universal definition (J-MINUET). Circ J 79(6): 1255-1262, 2015. PMID: 25912696. DOI: 10.1253/circj.CJ-15-0217

2 Bray F, Ferlay J, Soerjomataram I, Siegel RL, Torre LA and Jemal A: Global cancer statistics 2018: GLOBOCAN estimates of incidence and mortality worldwide for 36 cancers in 185 countries. CA Cancer J Clin 68(6): 394-424, 2018. PMID: 30207593. DOI: $10.3322 /$ caac. 21492

3 Mukai M and Oka T: Mechanism and management of cancerassociated thrombosis. J Cardiol 72(2): 89-93, 2018. PMID: 29588087. DOI: $10.1016 /$ j.jjcc.2018.02.011

4 Totzeck M, Schuler M, Stuschke M, Heusch G and Rassaf T: Cardio-oncology - strategies for management of cancer-therapy related cardiovascular disease. Int J Cardiol 280: 163-175, 2019. PMID: 30661849. DOI: 10.1016/j.ijcard.2019.01.038

5 Darby SC, Cutter DJ, Boerma M, Constine LS, Fajardo LF, Kodama K, Mabuchi K, Marks LB, Mettler FA, Pierce LJ, Trott KR, Yeh ET and Shore RE: Radiation-related heart disease: Current knowledge and future prospects. Int J Radiat Oncol Biol Phys 76(3): 656-665, 2010. PMID: 20159360. DOI: 10.1016/ j.ijrobp.2009.09.064

6 Thygesen K, Alpert JS, Jaffe AS, Chaitman BR, Bax JJ, Morrow DA and White HD: Fourth universal definition of myocardial infarction (2018). J Am Coll Cardiol 72(18): 2231-2264, 2018. PMID: 30153967. DOI: 10.1016/j.jacc.2018.08.1038

7 McKee PA, Castelli WP, McNamara PM and Kannel WB: The natural history of congestive heart failure: The Framingham study. N Engl J Med 285(26): 1441-1446, 1971. PMID: 5122894. DOI: $10.1056 /$ nejm 197112232852601

8 Killip T, 3rd and Kimball JT: Treatment of myocardial infarction in a coronary care unit. A two-year experience with 250 patients. Am J Cardiol 20(4): 457-464, 1967. PMID: 6059183. DOI: 10.1016/0002-9149(67)90023-9

9 TIMI Study Group: The thrombolysis in myocardial infarction (TIMI) trial. Phase I findings. N Engl J Med 312(14): 932-936, 1985. PMID: 4038784. DOI: 10.1056/nejm198504043121437

10 Cannon CP, Gibson CM, Lambrew CT, Shoultz DA, Levy D, French WJ, Gore JM, Weaver WD, Rogers WJ and Tiefenbrunn AJ: Relationship of symptom-onset-to-balloon time and door-toballoon time with mortality in patients undergoing angioplasty for acute myocardial infarction. JAMA 283(22): 2941-2947, 2000. PMID: 10865271. DOI: 10.1001/jama.283.22.2941

11 De Luca G, Suryapranata H, Zijlstra F, van 't Hof AW, Hoorntje JC, Gosselink AT, Dambrink JH and de Boer MJ: Symptomonset-to-balloon time and mortality in patients with acute myocardial infarction treated by primary angioplasty. J Am Coll Cardiol 42(6): 991-997, 2003. PMID: 13678918. DOI: 10.1016/s0735-1097(03)00919-7

12 Portenoy RK: Cancer pain. Epidemiology and syndromes. Cancer 63: 2298-2307, 1989. PMID: 2655867. DOI: 10.1002/10970142(19890601)63:11<2298::aid-cncr2820631140>3.0.co;2-a

13 Marcus NJ: Pain in cancer patients unrelated to the cancer or treatment. Cancer Invest 23(1): 84-93, 2005. PMID: 15779871. DOI: $10.1081 / \mathrm{CNV}-200046516$

14 Saka B, Kaya O, Ozturk GB, Erten N and Karan MA: Malnutrition in the elderly and its relationship with other geriatric syndromes. Clin Nutr 29(6): 745-748, 2010. PMID: 20627486. DOI: $10.1016 /$ j.clnu.2010.04.006 
15 Schatz IJ, Masaki K, Yano K, Chen R, Rodriguez BL and Curb JD: Cholesterol and all-cause mortality in elderly people from the Honolulu Heart Program: A cohort study. Lancet 358(9279): 351-355, 2001. PMID: 11502313. DOI: 10.1016/s0140-6736(01) $05553-2$

16 von Meyenfeldt M: Cancer-associated malnutrition: An introduction. Eur J Oncol Nurs 9(Suppl 2): S35-S38, 2005. PMID: 16437756. DOI: 10.1016/j.ejon.2005.09.001

17 Knight K, Wade S and Balducci L: Prevalence and outcomes of anemia in cancer: A systematic review of the literature. Am J Med 116(7): 11-26, 2004. PMID: 15050883. DOI: 10.1016/ j.amjmed.2003.12.008

18 Yeh ETH and Bickford CL: Cardiovascular complications of cancer therapy: Incidence, pathogenesis, diagnosis, and management. J Am Coll Cardiol 53(24): 2231-2247, 2009. PMID: 19520246. DOI: 10.1016/j.jacc.2009.02.050

19 Nordmann AJ, Hengstler P, Harr T, Young J and Bucher HC: Clinical outcomes of primary stenting versus balloon angioplasty in patients with myocardial infarction: a meta-analysis of randomized controlled trials. Am J Med 116(4): 253-262, 2004. PMID: 14969654. DOI: 10.1016/j.amjmed.2003.08.035

20 Kastrati A, Dibra A, Spaulding C, Laarman GJ, Menichelli M, Valgimigli M, Di Lorenzo E, Kaiser C, Tierala I, Mehilli J, Seyfarth M, Varenne O, Dirksen MT, Percoco G, Varricchio A, Pittl U, Syvanne M, Suttorp MJ, Violini R and Schomig A: Meta-analysis of randomized trials on drug-eluting stents $v s$. bare-metal stents in patients with acute myocardial infarction. Eur Heart J 28(22): 2706-2713, 2007. PMID: 17901079. DOI: 10.1093/eurheartj/ehm402

21 Velders MA, Boden H, Hofma SH, Osanto S, van der Hoeven BL, Heestermans AA, Cannegieter SC, Jukema JW, Umans VA, Schalij MJ and van Boven AJ: Outcome after ST elevation myocardial infarction in patients with cancer treated with primary percutaneous coronary intervention. Am J Cardiol 112(12): 1867-1872, 2013. PMID: 24063839. DOI: 10.1016/ j.amjcard.2013.08.019
22 Jovenaux L, Cautela J, Resseguier N, Pibarot M, Taouqi M, Orabona M, Pinto J, Peyrol M, Barraud J, Laine M, Bonello L, Paganelli F, Barlesi F and Thuny F: Practices in management of cancer treatment-related cardiovascular toxicity: A cardiooncology survey. Int J Cardiol 241: 387-392, 2017. PMID: 28365180. DOI: 10.1016/j.ijcard.2017.02.154

23 Yokoyama H, Higuma T, Endo T, Nishizaki F, Hanada K, Yokota T, Yamada M, Okumura K and Tomita H: Prognostic impact of body mass index and culprit lesion calcification in patients with acute myocardial infarction. Heart Vessels 34(12): 1909-1916, 2019. PMID: 31144097. DOI: 10.1007/s00380-019-01439-5

24 Liu M, Chan CP, Yan BP, Zhang Q, Lam YY, Li RJ, Sanderson JE, Coats AJ, Sun JP, Yip GW and Yu CM: Albumin levels predict survival in patients with heart failure and preserved ejection fraction. Eur J Heart Fail 14(1): 39-44, 2012. PMID: 22158777. DOI: $10.1093 /$ eurjhf/hfr154

25 Felker GM, Adams KF, Jr., Gattis WA and O'Connor CM: Anemia as a risk factor and therapeutic target in heart failure. $\mathrm{J}$ Am Coll Cardiol 44(5): 959-966, 2004. PMID: 15337204. DOI: 10.1016/j.jacc.2004.05.070

26 Rauchhaus M, Clark AL, Doehner W, Davos C, Bolger A, Sharma R, Coats AJ and Anker SD: The relationship between cholesterol and survival in patients with chronic heart failure. $\mathrm{J}$ Am Coll Cardiol 42(11): 1933-1940, 2003. PMID: 14662255. DOI: $10.1016 / j$ j.jacc.2003.07.016

27 Prenner SB, Kumar A, Zhao L, Cvijic ME, Basso M, Spires T, Li Z, Yarde M, Bhattacharya P, Zamani P, Mazurek J, Wang Z, Seiffert D, Gordon DA and Chirinos JA: Effect of serum albumin levels in patients with heart failure with preserved ejection fraction (from the TOPCAT trial). Am J Cardiol 125(4): 575-582, 2020. PMID: 31843232. DOI: 10.1016/j.amjcard.2019.11.006

Received September 12, 2020

Revised September 24, 2020

Accepted September 25, 2020 